\title{
The Regime of Self-Evaluation: Self-Conception for Teachers and Schools
}

\author{
Alison M. Brady
}

This is an Accepted Manuscript of an article published by Taylor \& Francis in the British Journal of Education Studies on the $11^{\text {th }}$ of April, 2016, available online:

http://www.tandfonline.com/doi/full/10.1080/00071005.2016.1164829.

\begin{abstract}
Self-evaluation in inspection policy has become a global phenomenon. The idea is that it increases levels of teacher and school autonomy, wherein both schools and teachers have more ownership and responsibility over their work. In turn, such a process has allowed for greater accountability, which is then said to provide high quality education and, therefore, greater competitive advantage amongst knowledge-based economies. In both England and Ireland, self-evaluation has become a demanding procedure that is meant to complement external inspections of schools and teachers. In this article, I will argue that self-evaluation, whilst having the potential to become a worthwhile endeavour, does not live up to its name. In the first instance, the criteria used for self-evaluation are not internally generated but externally imposed. Thus, I would like to discuss the extent to which visions of 'good' or 'bad' education developed by inspecting bodies influence the way in which teachers and schools assess themselves. Furthermore, I will raise questions as to what appropriate criteria for teaching might look like. In doing so, I shall try to show that what is now current is a debased form of self-evaluation that is not only detrimental to the self-perception of teachers, but inadequate to what any coherent notion of the 'self' might be. In light of work by the philosopher Charles Taylor in particular, I will argue that the self is not something that can be examined in the way that is imagined in these inspection systems but is rather something dynamic and unfixed, constituted within a wider community of practice and, therefore, not amenable to evaluation in quite the way that is supposed.
\end{abstract}

Key words: Self-evaluation policy, inspection, the self, accountability, autonomy 


\section{Introduction}

A culture of evaluation has burgeoned in the recent past, and education is not exempt from this. For decades, inspecting bodies such as Ofsted have been criticised by teachers and policy analysts as instruments of the neo-liberal agenda in schools, applying, so it is alleged, superficial criteria of good practice without any consideration for the cultural, economic or social factors that influence their perceived successes or shortcomings (Richards, 2001, 2015). Such systems of inspection have led to the formation of much-contested league tables, and there is evidence that these have driven the wedge even deeper into an already segregated community (Coldron et al., 2010; Ball, 2003a; Ball, 2003b; Allen and Vignoles, 2007). Despite this, Ofsted still manages to maintain a powerful position in the field of education, and in some quarters, its results are highly regarded and respected. The neo-liberal tendencies evident here are complemented by a perception of the ostensible needs of knowledge-based economies - the accountability of education not only to pupils, but to society at large, the commoditisation of viable workforces, the marketisation of curricula and schools, and the transferability of 'good practice' across not only school walls, but also national borders - all in an effort to boost levels of competitive advantage in the global economy.

School inspection has taken another turn in recent years, however. Instead of merely external inspections, which applied criteria equally to all schools and their staff, the idea of 'selfevaluation' has become a prevalent theme in the field of educational policy. Teachers and schools are encouraged to formulate their own development plan, to discuss their own perceived strengths and weaknesses, thus fostering collegiality and cohesiveness in terms of the school's own mission and aspirations for improvement (MacBeath, 2006). It seems, therefore, that the likes of Ofsted have taken on board the varying nature of schools, their uniqueness in terms of their student body, and teaching and management styles.

Indeed, there seems to be an inversion of sorts in terms of the general direction of school and teacher inspection in recent years. What may have traditionally been deemed as a more 'topdown' approach, where Ofsted employed specific criteria to judge the practice of teaching in schools, has been replaced with a more 'bottom-up' venture, where teachers and schools are tasked with evaluating themselves, using the idea of 'intelligent' or 'robust' accountability (Hislop, 2012; Miliband, 2004), or 'smart regulation' (Hislop, 2012) as their guide. It is difficult to argue with such logic. Surely this is a desirable new direction, given some of the criticisms that were launched at the entire inspection process in the past (Denison, 2005).

Or so, perhaps, it seems. The autonomy supposedly inherent in this new turn in inspection becomes quite questionable when one considers, for example, that the framework for selfevaluation in both countries is inherited almost exclusively from the inspectorates' own criteria for good or bad teaching (MacBeath, 2006; McNamara and O'Hara, 2008), and are therefore not generated by each of the schools themselves. Could we argue that this new approach, however true to the notion of self-determination it seems, is not enacted in a way that would be more attuned to what true self-evaluation might reasonably be held to stand for? When the ways in which teachers evaluate themselves naturally depend upon externally produced standards, can we still call it self-evaluation? It seems that the lines of externality and internality have become blurred. What was traditionally the task of the external inspector 
becomes enacted on an internal level. Self-evaluation becomes merely a form-filling exercise without merit, and any hope of improving practice is very much likely to suffer as a result.

What exactly is 'self-evaluation'? Before embarking on a discussion of what is at stake in the policy literature surrounding this topic, it is worth noting that, indeed, self-evaluation is a process that is generally undertaken by the school as a whole, in conjunction with teachers individually. Teaching is not something that exists in isolation. Policy literature seems to suggest that a collaborative approach to both teaching and self-evaluation is important, which would therefore necessarily involve taking into account the views of other stakeholders such as parents and pupils (Ofsted, 2015c; Ofsted 2015d; DES (Ireland), 2012). Although this is clearly a vital element in the self-evaluation process, the argument here will more so focus on the impact of such policy on the practice of teaching in particular, and on what it means to be a teacher tasked with self-evaluating.

Where does the 'self' fit into this process? There can certainly be unproblematic uses of the prefix self-, which I shall consider further at a later stage in the article. It is at least worth registering now that the prefix can be given a subject sense or an object sense, where the emphasis is respectively on the agent or on the possessor of various qualities and characteristics. Is it that the self is the object of the evaluation, the self being something which is not considered inherent to the person as such, but rather a mechanistic array of various qualities which can be 'objectively' examined? Or is it, rather, that the self is the subject of the evaluation - the teaching self performing the evaluation in a more introspective, somewhat 'soul-searching' self-examination? In this sense, one's personhood is tied to the way in which one behaves in a classroom, to the way in which one understands modes of teaching and learning, and to the way in which one interprets one's role as an educator. However, when, as self-evaluation policy seems to indicate, we have an oscillation between the self-as-object and the self-as-subject, self-evaluation becomes a systematically unsteady practice, a constant striving towards evaluating a self through it-self.

The issue I would like to specifically focus on, therefore, relates to the way in which this degraded version of self-evaluation is in danger of seeing the self as an appendage. In doing so, the self may become interpreted as something which can be removed and analysed without any reference to that to which it is attached. It may be conceived as something necessarily abstract, with its own essence, capable of being methodically examined in a way that is external to the person and to the culture and context in which that person has developed and continues to be determined by. This would impose an image of the self as a component only capable of change through instrumentalised reflection, prescribed by externally defined mandates of what it means to be a 'good' teacher.

\section{Self-Evaluation in Ireland: Debased Practices?}

In 2003, the Irish government introduced 'Looking at Our Schools', (herein known as LAOS) (DES (Ireland), 2003), a policy document which, for the first time, announced its plans to begin systematic inspections of teachers and schools across the country. Prior to this, inspections in schools had virtually ceased to exist, or at the most, were very sporadic in nature (McNamara and O'Hara, 2006). ${ }^{\mathrm{i}}$ As a result, teachers in Ireland are now receiving an 
'unprecedented level of monitoring and evaluation of their work' (MacRuairc et al., 2008, p. 502). ${ }^{\text {ii }}$

At present, the school evaluation procedure in Ireland is a combination approach between both external and internal inspection, with a seemingly heavier emphasis on self-evaluation and development planning of schools themselves (Department of Education and Science (Ireland), 2003). After an extensive pilot was conducted, the Department of Education and Science ${ }^{1}$ decided to introduce both Whole School Evaluation: Management, Leadership and Learning (also known as WSE-MLL) (DES (Ireland), 2011) and Subject Inspections (DES (Ireland), 2004) as the main vehicles for external assessments of both secondary and primary schools across the country. Similar to the case in England, external evaluations in Ireland focus a great deal on so-called objective information through data gathering, including the use of school information forms, statistical information regarding state exam results, pupilteacher ratio and enrolment patterns. The main basis of the judgements of the Inspectorate, akin to the case of Ofsted in England, is on a number of quality indicators outlined in LAOS (DES (Ireland) 2003). The role of the Inspectorate, delineated in the Education Act of 1998, does not only encompass the provision of external evaluations in schools, but is also meant to foster a culture of self-evaluation, providing support and advice to schools who were charged with undertaking development planning for themselves (DES (Ireland), 1998). This new inspection policy specifically focused on the rhetoric of greater school autonomy, with a deemphasis on such notorious ideas as accountability and performance measurements. The extent to which what is happening in practice is a corruption of what was initially anticipated and, hence, its potentially distorting view of the teaching self, is what I would like to address here.

Emphasised throughout the policy literature is the idea that the results of the evaluation were meant to signal the potential for improvement on behalf of the school, as something which should be viewed positively rather than as a means to formulate unfair league tables upon

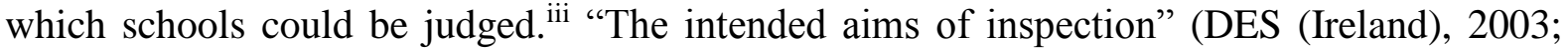
2004; DES (Ireland) 2011) are laid out using vague notions regarding the continuance of improving quality in education, without any salient aims or goals. On the other hand, LAOS (2003), the main framework behind both the WSE-MLL (2011) and the Subject Inspection (2004) criteria, consist of a colossal list of self-evaluation themes, the idea being that such themes would directly inform self-evaluative practice. These externally imposed criteria, rather than being internally generated in the first instance, constitute quite a debased of notion of what self-evaluation entails, and indeed, what the very nature of teaching and the teaching self consist of.

Following on from a speech given by the Chief Inspectorate, Harold Hislop, who, with respect to the 2012 PISA results (OECD, 2012), called for greater levels of quality assurance across Irish schools, a number of new initiatives were proposed which aimed at achieving just that. Hislop (2012) argued that the external aspect thus far had been much too elaborate and time-consuming and thus, would need to be significantly reduced if it was to remain a sustainable practice. He criticised the broadening and obfuscating of criteria used to evaluate

\footnotetext{
${ }^{1}$ The Department of Education and Science in Ireland officially changed its name to the Department of Education and Skills in 2010, and will herein be referred to as DES (Ireland).
} 
schools, as a more clearly defined set of standards could be used by Inspectorates in order to ensure equal assessments for all schools, as well as a high level of transparency and fairness. ${ }^{\text {iv }}$ What he refers to as a 'robust self-evaluation' would require not only this, but also sufficient training in the art of data collection, thereby further informing their own self-evaluation practices.

Given these definitions and requirements, what exactly then, for Hislop, is self-evaluation? It is clearly not the case that teachers evaluate themselves, for themselves, using their own perceptions, criteria and beliefs about teaching, presumably informed by the wider context in which they work. The criteria used are in themselves problematic, as will be explored below. Furthermore, it has ruled that teachers must now be completely 'objective' in their own evaluation, the only way possible being to separate oneself from their practice, and ultimately from their selves.

As a result of the new direction proposed by Hislop, ex-education minister Ruairí Quinn decided to release a guide to self-evaluation that same year, which explicitly accounts for the merits of a self-evaluation approach to inspection, and how, as a continuous process, it is now mandatory in all State schools. The document (DES (Ireland), 2012), perhaps somewhat patronisingly, gives its users prescriptive, step-by-step manuals on how to self-reflect, on what their definition of self-evaluation is, as well as tabulated diagrams of the various outcomes which self-evaluation processes should aim to achieve.

One could certainly not argue that this document is not thorough, so thorough in fact, that it leaves very little room for the teacher's own self to be present in the evaluation, their own criteria for good teaching to be developed or even considered, despite its apparent aims. With its preoccupation with ensuring that self-evaluation is taken seriously, and perhaps also with allowing for certain cost-saving measures by inverting the process of evaluation, this document is evidence of the fact that we have forgotten what internal evaluation is supposed to be - an evaluation of the self, in terms of that self, the teaching self being that which is shaped within a larger community of practice. Rather, it has inflicted its own definition of 'good' and 'bad' teaching, and how to spot it, onto the selves of teachers, making what is supposed to be a spontaneous and self-generated process into a bureaucratic, externally produced, standard-driven procedure, which extrapolates the self into some malleable entity, and which disallows any genuine self-reflection from taking place by suffocating it with singular, outer-mandated visions of education.

\section{Self-Evaluation in England: A History of Burgeoning Control}

Although the history of England's inspection regime is quite different from that of Ireland, the rationale behind it is strikingly similar. The Great Debate in education, sparked by the then-Prime Minister James Callaghan, is still ongoing (Callaghan, 1976). When New Labour would-be Prime Minister Tony Blair gave a similar speech 20 years later (Blair, 1996), however, the tone had dramatically changed. Education now seemed to be more so focused on raising standards of achievement, about holding teachers accountable for their performance, and seemed to discourage different visions of education, which Callaghan was keen to promote. Just a few years previously, Ofsted was established in place of the previous 
HMI modes of inspection (Government of the United Kingdom, 1992). It remains problematic throughout the field in education, and although severely criticised in academic literature (e.g. Case et al., 2000; Richards, 2001, 2015; Rosenthal, 2004; Avison and de Wall, 2008), still holds a significant place in the education system of England.

With New Labour's re-election in 2001, self-evaluation became a central tenet in evaluation policy. Furthermore, with the hope of fostering the so-called 'New Relationship with Schools', the minister for school standards in 2004, David Miliband, promoted this more positive model of inspection, too seeing it as an effective cost-saving measure whilst useful for retaliating against the destructive strains that existed between the government and schools following the era of Thatcher. Dissolving such tensions did not mean that Miliband (2004) would agree to being 'soft on teachers', as previous opponents would have claimed, but it would at least allow for some level of greater school autonomy, or so one might hope (Miliband, 2004; Government of the United Kingdom, 2006).

This new relationship had three main aims - to have a more effective accountability framework through the promotion of self-evaluation, to simplify the school improvement process by reducing the level of direct State involvement, as well as a greater flow of information and data between schools, parents and governmental bodies (Miliband, 2004; DfES (U.K.), 2006; MacBeath, 2006). With the use of a Self-Evaluation Form ${ }^{2}$, invariably provided by Ofsted, it was argued that schools would no longer be subject to externally imposed criteria for development, or at least a less rigorous version than what had previously been in place. This would then serve as a basis for the external Ofsted inspection, allowing the evaluation process to be, according to Miliband (2004), sharper, shorter and therefore, more frequent. Although Ofsted specifically stated that the Self-Evaluation Form was not self-evaluation per se, this message seems to have been somewhat lost amidst the education community (MacBeath, 2006). ${ }^{\mathrm{v}}$

What is the purpose of self-evaluation for Ofsted? According to them $(2013)^{3}$, it is vital in order to ensure that the highest standards of teaching are met, and that pupils are provided with the best possible learning experience. But where do these standards come from? Although completing the self-evaluation form is optional, if utilised and submitted to Ofsted it will be used to judge teacher's awareness of their own perceived strengths and weaknesses, as well as how such teachers have established such self-perceptions, and whether or not such self-perceptions are compatible with their own, over-arching judgements. Hence, this reveals where standards of judgement can be sourced from, and if one wants to receive a favourable self-evaluation report, the map to such attainment has been clearly marked by Ofsted itself.

\footnotetext{
${ }^{2}$ The Self Evaluation Form has more recently been referred to as to Self Evaluation Document in policy literature. (See, e.g., Ofsted (2015a)).

${ }^{3}$ The Ofsted inspection framework of 2013 has since been replaced with the 'Common Inspections Framework' in September 2015 (Ofsted, 2015b). Whilst this new framework does not, at length, discuss self-evaluation, the new school inspections handbook and the self-evaluation document guidance (Ofsted, 2012, 2015c) still requires that Inspectors, upon their arrival to the school, should be able to look at evidence that such processes are being undertaken at the school in the form of a school self-evaluation document, unspecified in terms of format or length.
} 
Indeed, the reductive technologies employed by Ofsted have been criticised on numerous occasions. Some argue that they simply cannot achieve what they claim they can - wholly objective judgements of the success or failure of schools (Richards 2001; 2015). Others are disheartened by the neo-liberal visions of education it purports, and the debased notions of what constitutes 'good teaching' it continues to espouse (Lefstein, 2013). Many have accounted for the detrimental effect Ofsted has had on institutions and their staff, including low staff morale and burn out by those over-burdened with an impossible workload (Rosenthal, 2004; Clapham, 2015). The biggest worry addressed here, however, is how this corruption of genuine self-evaluation is perhaps imperceptibly yet irreversibly so, changing what it means to be a 'teaching self', and through employing tactics, such as excessive monitoring, self-surveillance and also through 'reward systems' such as pay-related performance, an idea of the self as something instrumental, external and stagnant becomes inescapable.

\section{Innocent Policy and What It Means to be a Teacher}

Thus, we have two different contexts attempting to implement the same system which is meant to allow for greater school and teacher autonomy, whilst in practice, seems to be doing the exact opposite. One began with a more cautious approach, only to be made extreme following the global recession. The other was always quite extreme, one could argue, but tried to be less so, only to merely invert the process instead of improving it. With more autonomy comes greater accountability. Self-evaluation is supposed to mean that inspectors will no longer be the only source which dictates what teachers should do in their classroom. But when the criteria used to evaluate oneself are generated by the same framework, this is clearly the case. Now, teachers are made responsible for their own assessments, using standards that are not necessarily theirs (Simons, 2014a; 2014b). This is presumably to allow for the transference of good practice, as well as higher levels of transparency. What it does, however, is misdirect teachers into attempting to objectively examine something, i.e. the 'self', which is subject to constant change, or in the words of Taylor (1989; 1991), constituted within a continuous struggle.

The previous two sections of the article briefly outlined some of the policy literature in both Ireland and England that correlates with the process of self-evaluation. This outline is admittedly quite over-simplified, but in doing so, the article is more concerned with attuning to some of the dangers of such a seemingly harmless development in inspection policy, and what questions this might raise in relation to the self. This might lead one to question if I am erecting a straw-man argument here. Indeed, emphasised throughout self-evaluation literature is the necessity of creating a dialogue with the wider school community, including students, governors and parents among others. Certain tools for interacting with this community are also provided. But very little is said about what it actually means for a teacher, and indeed a school, to be a part of a wider community of practice. What has been discussed demonstrates that there is at least a facet of the policy literature on self-evaluation which accounts for the nature of teaching in a more individualised rather than existentially rich way. Not only does this subtle yet insidious ideal seem to permeate the very notion of what teaching is, it also says something about what we consider the self to be in the wider context, i.e. as an unchanging essence of sorts. 
Before endeavouring to outline the various issues that arise from the particular kind of perception of the self as something 'fixed' evident in self-evaluation policy, it is important to briefly point towards the use of specific criteria in the process of inspection. This issue warrants more attention than I am able to give it here, however, it is worth registering the dangers of using such kinds of 'checklist' criteria in the field of teaching, particularly as it relates to a debased vision of what constitutes a 'self'.

\section{A Problem of Criteria}

The dictionary definition of a criterion is "a principle or standard by which something may be judged or decided", coming from the Greek kritérion, which translates as an 'instrument or means of judging' (Oxford Dictionary, 2010). Therefore, the acts of judgment and of producing or applying sets of criteria are closely linked. This definition seems to align with what a general, technicist understanding of 'criteria' for the assessment of teaching.

But there is a vital element of criteria that such a definition fails to fully recognise. How is a practice possible without criteria? Criteria are much more than that which can be collated into a checklist of sorts. They are the very foundations upon which a community is forged and sustained. Every practice that we undertake as members of a specific community is underlined by certain criteria for what is deemed appropriate, relevant or even necessary and what is not. The more we try to record such things, the more confusing and elusive they become. What are the criteria for speaking to a friend in public? What are criteria for sitting on a chair? We can come up with a list of particular ways in which one should behave in certain circumstances, but this list will never be fully comprehensive. This is not only because criteria are sometimes obscure, too multitudinous to fully account for yet perpetually present nonetheless. It is also because communities themselves are dynamic, ever flourishing and therefore subject to constant, albeit often subtle, change, similar to how a more accurate understanding of the self may be conceived.

There are complex interactions of signs, cues or signals in communities which are similar to what takes place in teaching, and more pervasively so given that the teacher is 'present' in the classroom in a somewhat particular and immeasurable way. Because of this, it seems nonsensical to use very specific, 'checklist' criteria to judge it as such because it is so varied and variable, because there is not always 'one right way' of doing things, and because one simply cannot pinpoint what it is exactly that makes good teaching. Furthermore, it would be difficult, if not impossible, to apply singularised criteria for measuring or explaining this particular 'presence' in the classroom. We can give advice, tips, nuggets of wisdom that we may have collected from experience or practice in similar situations. We can even make certain expectations of teaching clear - safe-guarding of children, punctuality, expectation of care and commitment. These could be made into a 'checklist' of sorts because they are quite unambiguous. But the real standards that matter in teaching cannot be subsumed in the same way. They can only be worked out within a community of practice, within which we can develop reasonable standards for teaching, standards which may, and should be subject to change, such as a community of practice is. Such standards are necessarily, and indeed inevitably, open to interpretation or different manifestations in practice. With a form of self- 
evaluation that sees teaching in this debased form, such discussions and reasonable conversations with relation to standards remain fixed and is not only misrepresentative of the nature of teaching, but debases both it and the practice of self-reflection itself to a mere form filling exercise. Furthermore, it corrupts the very notion of the self which is at stake in this discussion.

\section{A Question of the Self}

The conception of the self in teaching may be said to be intimately linked to neo-liberal views of education. In order to perhaps better understand the rise of neo-liberal values, it may be useful to consider the 'three malaises' which have infected modern culture, according to Taylor (1989; 1991). Briefly, these three illnesses as described by Taylor (1989; 1991) include the proclivity of modernity to emphasise the importance of individualism, the rise of instrumental reason and finally, what Taylor $(1989$; 1991) calls a 'soft despotism'. An overemphasis on the value of individualism has led to a demise in the sense of belonging people once felt when they were aware of their 'proper place' in society, based on a belief in hierarchical structures, dismantled by an overall disenchantment with the world due to the prevalence of instrumental reason. With this penchant in modernity for individualism, the self becomes a central tenet, which 'both flattens and narrows our lives, makes them poorer in meaning and less concerned with others or society' (Taylor, 1991, p. 4). Such nihilistic and narcissistic tendencies may have also led to an increase in the monitoring techniques employed by individuals on a daily basis, which may also explain the pervasive obsession with surveillance in audit culture.

Taylor's writings of the early 1990 s seem to be eerily prophetic of the gradual but relentless drive of neo-liberalism that was later to come. Education has been severely affected by this; we need only look at the emphasis that is placed on accountability, served alongside notions of greater autonomy and the seeming necessity of self-monitoring in order to achieve both mutually exclusive ends. But it is not merely education that is disturbed by neo-liberalism. Through the use of the mechanisms of self-evaluation, hidden by the outward agenda of autonomy, teachers are now being constituted as neo-liberal selves. ${ }^{\text {vi }}$

Rarely is the 'self' addressed in self-evaluation literature, however. The prefix of the 'self' has been widely used in innocuous ways, for example, to denote activities that can be completed without any help from other persons. It is worth registering the ambiguity between what might be thought of as subject and object senses in such usages. Sometimes, in the context of such expressions, the thing evaluated will be more or less external to the agent of the evaluation. If the tyre-pressure gauge at the garage is self-service, this means, on the one hand, that I and not the attendant will operate the pump. But it also turns attention to the thing that I will do, the object of attention, the checking of my tyres, which is after all the main focus of the exercise. When I do this, I shall be guided entirely by criteria that I only partly understand - the required pressures for the tyres on my car etc. These have been determined by expert engineers, and there is no need, nor room, for me normally to question them.

But let's take another case. Suppose, as a second example, that I am concerned about my blood pressure. I monitor myself using a machine I have at home. I do not fully understand 
the criteria for healthy blood pressure, but I know what numbers to look for and that if there is any severe deviation from the norm I should seek medical advice soon. As is the case with tyre pressure, it is unnecessary for me to comprehend such complicated matters, but I do need to know what to do. I place my trust in the expertise of medical staff who can situate such numerical results within a wider frame, and who will then retranslate the reading, if need be, so that I can grasp the problem in simpler language. Although in a sense it is intimately a part of me, my blood pressure can reasonably be perceived as a fact about my body rather than something that tells you or me who I am. My blood pressure is not part of my personhood. It is not necessarily tied to the context in which I reside nor the work I engage in.

In both the cases considered, I am self-monitoring and, to the extent that I am carrying out the evaluation myself, I am self-evaluating. In neither case is anyone likely to be in any confusion as to what is going on. But in the case of the self-evaluation of teachers, the term operates in an altogether more dubious way. In part, such self-evaluation can be taken to imply the self-monitoring of teachers against standards that are externally established and not open to reflection or interpretation. On the other hand, it might imply something more like self-examination, partly in the tradition of the reflective practitioner but also given a more existential edge in that it may reasonably involve my self-questioning about the quality of my engagement with my students and what I teach, about how I am affected by the experience of teaching. These are not idle questions because, as both experienced and trainee teachers will realise, teaching typically affects the person in profound ways, moving their life as a whole. And this reflects a level of personal investment and commitment that is crucial to good teaching.

In self-evaluation, we are asked specifically to evaluate the self. What could this mean? Surely, in neither case, does it fall into the same category as the innocuous usages of the 'self' mentioned above. Self-evaluation means evaluating one's very own personhood, a complex amalgamation of experiences and events which make up a self. Given that the criteria for good teaching are almost always externally generated in a 'checklist' format and therefore, applied equally regardless of context or internal differences, it seems clear that the version of self-evaluation being enacted in schools imagines the self as something which can be examined externally and mechanistically.

Partly due to Cartesian dualism and also the general rise of scientific discourse, amplified by the influence of new technology, with numerically inclined spreadsheets, there seems to be a hardening of the subject-object divide. Indeed, since Descartes, there has been a persistent separation of the self and the object of its enquiry. In self-evaluation, this dichotomy is also evident. Yet, in order to purport an alternative, more authentic vision of the practice itself, we need to dismantle the view of the self as an appendage. The self is not something that exists outside the bounds of context. It does not remain as an unchanged essence. It is continuously modified and reinvented through external influences, which govern the way in which a person behaves. It cannot be considered a-contextually, therefore but as something which is embedded within a persistently dynamic milieu, meaning that it, too, is dynamic in form. 
To evaluate the self requires that we evaluate a context individual to each person, the past and the present that affects how this self comes to be in practice. With the use of specific standards equally applied to all regardless of context, this poses a number of difficulties. In our attempts to remain objective and fair, we have lost our connection to the context which is vital for understanding the self. When we tried to introduce a way in which to include context, such as is the prime objective of self-evaluation, we end up with a long list of ingredients and a clearly demarcated manual on how to undertake this crucial task. Just as it is influenced by our socio-economic background, by our families, by our culture-related rules, by our community, among many others, it is also influenced by the perceived authority of expertise which dictate the way in which one views oneself as a teacher and the task of evaluating one's own performance. The fixing of inspection criteria comes to full realisation when the teaching self is the product of educational policy and not of one's own context and self-(re)formation. By using the word self-(re)formation, I want to avoid a term (formation) that would imply a completion, because the self is never fully formed but is perpetually transformed through our openness to new encounters, new 'horizons of significance' (Taylor, 1989; 1991), as well as the very communities in which we reside, which are subject to constant change themselves. We need to ask ourselves this: is such openness possible in the case of self-evaluation, when the self and the criteria by which it is evaluated are considered fixed?

\begin{abstract}
We are expected to develop our own opinions, outlook, stances to things, to a considerable degree through solitary reflection. But this is not how things work with important issues, such as the definition of our identity. We define this always in dialogue with, sometimes in struggle against, the identities our significant others want to recognize in us. (Taylor, 1991, p. 34)
\end{abstract}

In terms of teaching, the inspector, equipped with the authority of expertise, is most certainly a 'significant other', who influences how one identifies oneself as a teacher. But it is not only that. For what kind of a teacher would one be if one only listened to what the inspector said about their practice, if one was not attentively in tune with the needs of one's students, for example? And what of the reasons one chose to be a teacher in the first place? From where did such motivations arise? What noteworthy events in one's life, perhaps, formed this mindset of desiring to teach? Such motivations are the driving forces behind what might be reasonably considered 'good' or 'bad' teaching. They do not appear homogenous in nature, they do not arise out of a vacuum, and they cannot be measured in a fixed way, therefore. These are criteria which, external to the self, affect how it comes to be as such. When I speak of criteria in this sense, I am not talking about the sort of uniform, listed criteria that is used in current inspection policy. Criteria in the former sense are understood in relation to a specific form of initiation that we undergo when launched into a particular, pre-existing context, as was delineated above.

The community of practice in which teaching is undertaken links to what Taylor refers to as 'horizons'. In recognising the significance of such 'horizons', we can purport an idea of the self which does not exist in a void, but is embedded within a wider 'background of intelligibility' (Taylor, 1989; 1991) which allows us to determine what we consider to be important facets of life. These 'horizons of significance' (Taylor, 1989; 1991) are constituted by the context in which we reside and ultimately, the communities of practice in which such 
ideals or standards of the good are formulated and enacted. Such horizons, according to Taylor $(1989 ; 1991)$, cannot be suppressed or escaped from since they constitute the very being of the self.

In light of this, a discussion around which standards are important in teaching, some articulable, others less so, can ensue. This relates to the desirability, according to Taylor $(1989 ; 1991)$ of articulating these inescapable frameworks in which the self is (re)constituted. The criteria inherent in such frameworks demonstrate our commitment to a particular worldview as comprised through our socio-cultural background, our orientation towards the good, our sense of being in the world (Taylor, 1989; 1991). Such criteria are open to change, are dynamic, and can acquire a certain nuanced approach to being in the world. Since the self is constituted vis-à-vis a negotiation with and within the 'horizons of significance' that encapsulates it momentarily, the self, therefore, is also subject to continual formation and reformation.

The way in which we are committed to a certain community in which we reside, and the particular criteria that determine what is appropriate within that community and what is not, correlate to the commitment to certain standards or criteria of teaching, and those which are polluted as a result of external imposition via the neo-liberal agenda in education, such as through a technicist, overly bureaucratic approach to teaching and the prevalence of accountability measures and performativity (Simons, 2014a; 2014b). The issue with selfevaluation operated in this technicist way is that the only criteria or standards of good teaching arise from a specific, occasioned political view of the then-purpose of education. With being overly concerned with a degraded version of so-called 'objectivity', thus treating the self as something which can be examined in the same way, this thereby does not allow for a more accurate, dialogical conception of the self, or as the self as that which is always, unavoidably oriented towards some account of the good, or some vision of what worthwhile practice might look like (Taylor, 1989).

A form of self-evaluation understood in light of this, therefore, would necessarily involve a move towards greater consultation with important stakeholders such as parents and pupils, as well as an broad awareness of wider societal issues and needs, which will not serve to instrumentalise teaching as being for some (potentially) unattainable notion of the 'greater good', but will remain sensitive to the issues which may be affecting the way in which pupils, for example, are interacting with the material in class. Self-evaluation need not be conducted in isolation from this community of practice, but on the contrary. A reasonable conversation on those standards impossible to grasp in any concrete form, those standards which are subject to change, open to a varied manifestation in practice, those standards which are vital to teaching, and yet extremely elusive, can and should be discussed amongst those who are crucial to their understanding. The sharing of ideas, the informal discussions around pupil progress, even the spontaneous outbursts of emotion that often accompany the strenuous job of teaching - these should be encouraged rather than, as in the current practice, debased in a 'checklist' form. Self-evaluation needs to be dialogical, since the self is, in itself, a dialogical and dynamic entity. But if we are to examine the policy literature surrounding selfevaluation, and consider some examples of how it has been implemented in practice, we can see how this dialogical element is in danger of being lost. It may be the case that such consultation is encouraged throughout policy literature, a sort of 'bolted-on' component of 
school self-evaluation, yet even such dialogue is determined, to an extent, by inauthentic criteria (e.g. DES (Ireland), 2012), and more importantly, fails to recognise the way in which communities of practice have a direct correlation to what a reasonable vision of the self in teaching may be - not as separate from this community, but a changing landscape of what that community stands for.

Alongside the advances of the Enlightenment came the notion of 'self-determining freedom', à la Rousseau. This idea purported that one could decide what was best for oneself irrespective of and uninfluenced by those who surround us. Coupled with modernity's seemingly unending drive towards self-fulfilment, what one might call 'authentic' or 'good' is now considered merely in personal terms. This is something I wish to also avoid here. In thinking of the self in this way, we begin to treat other selves in a purely instrumental fashion.

Yet, if we are to accept the idea that the self is constantly formed and re-formed in dialogue with others, this instrumental view of the self becomes severely problematic. Our identity, and therefore our self, is forged and re-forged through what we have experienced or lived through thus far, the meaning that we apply to those experiences in retrospect and also, the orientation of the good towards which we direct ourselves in terms of the future, which is necessarily established through our understanding of the past. Furthermore, our understanding of this is very much constituted within the particular context in which we live. Hence, to view the self and others in a purely instrumental way causes stultification. We can no longer understand ourselves if we are abstracted from those experiences which have influenced us, which account for our differences, and which therefore necessarily means that a checklist, externally produced criteria equally applied to all individuals will no longer make any sense, especially if it is used to assess a self.

\section{Conclusion: A Way Forward?}

Hence, we have established, to an extent, why treating the self as something which can be understood 'objectively' is problematic. Thus, the policy of self-evaluation, which seeks to do precisely that for reasons inspired by neo-liberal ideology, as discussed previously, does not live up to its name. Rather, it is merely an inversion of the older system of external evaluation which has been severely criticised as, consequentially, not being contextual enough. Self-evaluation attempted to combat this, but in my mind at least, failed to do so in practice. Subsequently, the more thorough we become in setting forth this criteria, the more fixed it becomes, and the less room there is, therefore for the self to be present.

So where do we go from here? Should we abandon school inspections entirely? Are there no models which allow for the context of the school, and the context of the teacher? Or is such an instrumental view of education, and of the self, simply inescapable?

To quote MacBeath (2006, p. 143) on what genuine self-evaluation is: 
"It happens most of the time spontaneously and intuitively. It is embedded in the teacherpupil relationship, in the daily discourse of the staffroom. It takes place at the photocopier and in the administration and management offices. It is implicit in the work that teachers take home with them and in the planning and preparation for the next lesson."

Taylor introduces the notion of a 'continuous struggle', which I find to be particularly pertinent to our cause. In attempting to 'find oneself', we are met with a necessary struggle. We struggle against the changing idea of who we are, of what we stand for. It is through this struggle that authentic self-evaluation, as described by MacBeath (2006), takes place. Selfevaluation should not be based on a clearly defined prescription of what constitutes 'good' practice. Once we allow a more authentic understanding of the self, which necessarily struggles throughout the discovery of what it is that constitutes our view of a worthwhile livelihood and practice, a view of the self that is open and receptive to constant change, through our encounters with others or with situations we may not have previously thought were possible, can a more robust version of self-evaluation take place. We must try to avoid articulating the self in binary language, which sees it as something which can be abstracted from context and examined accordingly. This struggle will most likely never be resolved, but such is the beauty of residing in a world where new encounters can occur, and where the self can be continually be reformed, reinvented and re-forged.

Not only is this conception of the self vital for a more authentic understanding of teaching, it also raises fundamental questions about education itself. If we are to understand the self in teaching as something dynamic, there is reason to argue that both the school and the very nature of education should also be understood in the same light. Should education be merely a practice in conservation that correlates with a 'fixed' notion of the self? Or should it be considered as something that goes beyond replicating the past, thus having implications for such issues as that which relates to social justice? Perhaps it is only through addressing these issues of fixation and dynamism can such questions be considered.

\section{Reference List}

Allen, R. and Vignoles, A. (2007) What should an index of school segregation measure? Oxford Review of Education, 33 (5), 643-668.

Ball, S. (2003a) Class Strategies and the Education Market: The Middle Class and Social Advantage. London: Routledge.

Ball, S. (2003b) The teacher's soul and the terrors of performativity. Journal of Education Policy, 18 (2), 215-228. 
Blair, T. (1996) Speech given at Ruskin College Oxford, UK, December $16^{\text {th }}, 1996$. Available at: http://www.leeds.ac.uk/educol/documents/000000084.htm (accessed 10 Sept. 2013).

Callaghan, J. (1976) A rational debate based on the facts. Speech at Ruskin College Oxford, UK, October 18, $1976 . \quad$ Available at: http://www.educationengland.org.uk/documents/speeches/1976ruskin.html (accessed 10 Sept. 2013).

Case, P., Case, S. and Catling, S. (2000) Please show you're working: a critical assessment of the impact of Ofsted inspection on primary teachers. British Journal of Sociology of Education, 21 (4), 605-621.

Clapham, A. (2015). Post-fabrication and putting on a show: examining the impact of short notice inspections. British Educational Research Journal, 41 (4), 613-628.

Coldron, J., Cripps, C. and Shipton, L. (2010) Why are English secondary schools socially segregated? Journal of Education Policy, 25 (1), 19-35

Denison, P. (2005) Self-evaluation: a shift in mind-set. Times Educational Supplement. 2 September, p. 34.

Department of Education and Skills (Ireland) (2012) School Self-Evaluation Guidelines for Post-Primary Schools. Available at: https://www.education.ie/en/Publications/Inspection-Reports-Publications/EvaluationReports-Guidelines/sse guidelines_post_primary.pdf (accessed 10 Sep. 2013).

Department of Education and Skills (Ireland) (2011) A Guide to Whole School Evaluation: Management, Leadership and Learning (Dublin, Stationary Office).

Department of Education and Skills (Ireland) (2009) A Guide to Subject Inspection at Second Level (Dublin, Stationary Office).

Department of Education and Science (Ireland) (2003). Looking at our school (LAOS): an aid to self-evaluation in second-level schools (Dublin, Stationery Office).

Department for Education and Science (U.K.) (2015) The Framework of School Inspection. Available at: https://www.gov.uk/government/uploads/system/uploads/attachment_data/file/457194/T he_framework_for_school_inspection-.pdf (accessed 10 May 2015).

Foucault, M. (1979) Discipline and Punish: The Birth of the Prison (New York, Vintage Books).

Gordon, P., Dean, D. and Aldrich, R. (1991) Education and Policy in England in the Twentieth Century (London, The Woburn Press).

Government of Ireland (1998) Education Act (Dublin, Stationery Office).

Government of the United Kingdom (2006) Education and Inspections Act. Available at: http://www.legislation.gov.uk/ukpga/2006/40/contents (accessed 10. Nov. 2013).

Government of the United Kingdom (1992) Education (Schools) Act. Available at: http://www.legislation.gov.uk/ukpga/1992/38/contents (accessed 10 Nov. 2013). 
Hislop, H. (2012) The Quality Assurance of Irish Schools and the Role of Evaluation: Current and Future Trends. Presented at The Professor Seamus O' Suilleabháin Memorial Lecture, Maynooth, May 2, 2012.

Lefstein, A. (2013) The regulation of teaching as symbolic politics: rituals of order, blame and redemption. Discourse: Studies in the Cultural Politics of Education. 34 (5), 643659.

MacBeath, J. (2006) School Inspection and Self-Evaluation: Working with the New Relationship." (Oxon, Routledge).

MacRuairc, G. and Harford, J. (2008) Researching the contested place of reflective practice in the emerging culture of performativity in school: views from the Republic of Ireland. European Educational Research Journal, 7(4), 501-511.

Mooney-Simmie, G. (2012) The pied piper of neo-liberalism calls the tune in the Republic of Ireland: an analysis of education policy text from 2000-2012. Journal for Critical Education Policy Studies, 10(2), 485-514

McNamara, G. and O'Hara, J. (2008) Trusting Schools and Teachers: Developing Educational Professionalism through Self-Evaluation - Irish Studies (New York, Peter Lang Publishing Inc.).

NcNamara, G. and O'Hara, J. (2006) Workable compromise or pointless exercise? schoolbased evaluation in the Irish context. Educational Management and Leadership. 34, 564580 .

Miliband, D. (2004) Personalised learning: building a new relationship with schools. Speech at North of England Education Conference, Belfast, January 8, 2004.

OECD (2012) Programme for International Student Assessment (Paris, Organisation for Economic Co-Operation and Development).

OECD (1991) Review of national policies for education Ireland (Paris, Organisation for Economic Co-Operation and Development).

Ofsted (2015a) Ofsted examples of good practice in schools. Available at: https://www.gov.uk/government/collections/ofsted-examples-of-good-practice-inschools (Accessed 08. Feb. 2016)

Ofsted (2015b) Common inspection framework: education, skills and early years from September 2015. Available at: https://www.gov.uk/government/uploads/system/uploads/attachment_data/file/461767/T he_common_inspection_framework_education_skills_and_early_years.pdf (Accessed 08. Feb. 2016)

Ofsted (2015c) School inspection handbook: handbook for inspecting schools in England under section 5 of the Education Act 2005. Available at:

https://www.gov.uk/government/uploads/system/uploads/attachment_data/file/458866/Sc hool_inspection_handbook_section_5_from_September_2015.pdf (Accessed 08. Feb. 2016)

Ofsted (2012) Self evaluation document: guidance. Available at: https://www.gov.uk/government/uploads/system/uploads/attachment_data/file/203404/T A-00102-2012.pdf (Accessed 10. Nov. 2013) 
Ofsted (2013) The framework for school inspection. Available at: https://www.gov.uk/government/publications/the-framework-for-school-inspection (Accessed 10. Nov. 2013)

Ofsted (2006) Best Practice in Self-Evaluation: A Survey of Schools, Colleges and Local Authorities. Available at: http://dera.ioe.ac.uk/5988/1/Best\%20practice\%20in\%20selfevaluation $\% 20 \mathrm{~A} \% 20$ survey\%20of\%20schools, \%20colleges\%20and\%20local\%20authori ties\%20(PDF\%20format).pdf. (Accessed 10. Nov. 2013).

Richards, C. (2015) More outstanding nonsense: a critique of Ofsted criteria. FORUM. 57 (2), 233-238.

Richards, C. (2001) School inspection in England: a reappraisal. In Impact: No. 9 in a Series of Policy Discussions. Eds. C. Winch and R. Smith, (Philosophy of Education Society of Great Britain, London).

Rosenthal, L. (2004) Do school inspections improve school quality? Ofsted inspections and school examination results in the UK. Economics of Education Review, 23 (2), 143-151.

Sartre, J.P. (1943) Being and nothingness: An essay on phenomenological ontology. H. E. Barnes (trans.), (Routledge Classics, London and New York).

Simons, M. (2014a) Governing through feedback: from national orientation to global positioning. In World Yearbook of Education 2014: Governing Knowledge: Comparison, Knowledge-Based Technologies and Expertise in the Regulation of Education, ed. T. Fenwich, E. Mangez and J. Ozga, (Routledge, London).

Simons, M. (2014b) Governing education without reform: the power of the example. Discourse: Studies in the Cultural Politics of Education, 36 (5), 712-731.

Taylor, C. (1991) The Ethics of Authenticity. (Harvard University Press, Cambridge, MS and London).

Taylor, C. (1989) Sources of the Self: The Making of the Modern Identity. (Cambridge University Press, United Kingdom).

\section{NOTES}

\footnotetext{
'Due to the economic boom of the 1990s, as well as seemingly feeling pressured by the apparent implementation of an array of evaluation approaches internationally, further exacerbated by accusations from such influential bodies as the OECD (1991), the Irish government became increasingly concerned with securing the country in the realm of global, knowledge-based economies. The Irish education system was considered to be a key factor in ensuring such socio-economic progress.

iiThis is a stark contrast from the previous, individualistic nature of schools, maintained for a number of reasons, including resistance to inspection on behalf of the Teacher Unions (NcNamara and O'Hara, 2009), as well as the influence of the Catholic Church in purporting an image of the school as a kind of sanctuary, appropriately void of governmental involvement (Mooney-Simmie, 2012).

iiiThis message is somewhat disingenuous, however, when one considers the fact that, after the evaluation has been completed, such results are published on the Department's website, available to the wider public, and thus naturally informing parental choice and school image in a similar manner to the contested league-tables in such countries as England (DES (Ireland), 2003 and 2004; DES (Ireland), 2011).
} 
${ }^{i v}$ For Hislop (2012), the main reason why self-evaluation is avoided in schools is precisely because of a lack of detailed criteria provided to teachers in LAOS with which they can evaluate themselves, thus making teachers directionless and ill-advised of their own weaknesses and strengths.

${ }^{v}$ In a survey conducted by the National College of Leadership (MacBeath, 2006) which directly probed schools as to which self-evaluation framework they were adopting, the Ofsted SEF template proved to be the most popular. Their main rationale was that it was the most standardised and thus easily applied, and doing so would adequately prepare schools for any impending external inspections. More original or creative approaches became marginalised, despite aforementioned disclaimers from HMCI that Ofsted's form was not selfevaluation per se. According to the most recent policy literature (2015c), however, Ofsted has made clear that self-evaluation does not have to be of a specified format, length or level of detail. Conversely, when one considers the documentation on self-evaluation as provided on the Department for Education's website. On it, Ofsted offers examples of good practice in terms of self-evaluation from schools that have successfully attained the 'outstanding' status, presumably in order to give guidance to those schools failing to achieve the same. In one such example (2015a), the school's own criteria for how they self-evaluate effectively are curiously in line with Ofsted's own standards of good teaching - having high expectations of pupils, making staff feel accountable for the work they are involved in, utilising specific and targeted data collection which informs practice, monitoring and evaluating school processes on a regular basis. It may be that such generic aims are unarguably central to education, yet it is interesting to consider to what extent such targets arise from selfevaluation. (e.g. see also DfES 2006 surveys)

vi What Sartre refers to as 'the gaze' in 'Being and Nothingness' (1943) is particularly relevant here, as is Foucault's analysis of the Panopticon prison design in 'Discipline and Punish' (1979). The overall claim here is that the self, through technologies of surveillance, become fixed, either as an object in the perception of the Other, or as that which internalises certain mechanisms of discipline which are (initially) externally imposed. In self-evaluation, neo-liberal ideals of teaching in general is quite palpable, and such ideals 'fix' the teaching self in a similar way to what is discussed in both Sartre's and Foucault's work. Other thinkers such as Levinas and Derrida would also be useful in this discussion. 